\title{
Process and Potential Factors to Develop Problem Solving Competency in Learning Electrolysis
}

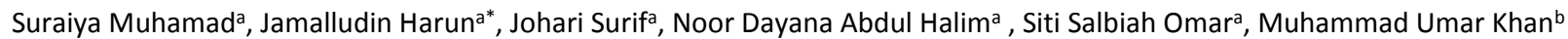 \\ ${ }^{a}$ Department of Educational Sciences, Mathematics and Creative Multimedia, Faculty of Education, Universiti Teknologi Malaysia,81310, UTM Johor Bahru, \\ Johor \\ ${ }^{b}$ Department of Education Foundation and Social Sciences, Faculty of Education, Universiti Teknologi Malaysia,81310, UTM Johor Bahru, Johor \\ *Corresponding author: p-jamal@utm.my
}

\begin{abstract}
This paper discusses a preliminary study which was undertaken to develop a model of authentic chemistry problem solving competency (PSC) in learning chemistry. Recent poor performance of Malaysian students in the Programme for International Students Assessment (PISA) on problem solving test could be due to a pervasive pattern of low application of higher order thinking skills (HOTS) in solving the open-ended problems in Malaysian teaching and learning scenarios. Hence, this study investigated how secondary school students solve open-ended problems in learning electrolysis and what are the underlying factors of their problem-solving competency. At the beginning, 112 chemistry students from a secondary school in Sarawak were selected as the participants. Semi-structured interviews and think aloud protocol (TAP) were conducted to five selected participants in order to investigate their problem solving processes practice. Quite similar findings have emerged: participants that scored with good score in chemistry problem solving ability test (CPSAT) have higher scientific knowledge and problem solving skills compared to low achieving participants. Scientific knowledge competency and problem solving skills have been identified as the major independent variables to develop chemistry problem solving competency. Outcomes from this study shall be used to design a module for one selected topic in chemistry and to develop a 'Model of Authentic Chemistry Problem-solving Competency' for school students in general.
\end{abstract}

Keywords: Problem-solving competency; high order thinking skills (HOTS); open-ended problem

(C) 2017 Penerbit UTM Press. All rights reserved

\subsection{INTRODUCTION}

Malaysian government aims universal access all the way through to secondary education, that will produce students who perform in the top third of international assessments, to provide equal and quality educational opportunities for all students. This is due to the rapid changes of global market which require competent citizen and hence demand a transformation in Malaysian national education. The role of formal education in school is not merely to transfer knowledge but also to apply the knowledge to produce future generation with HOTS to solve complicated problems in the real world especially in Malaysia. However, recent performance of Malaysian students in the Programme for International Students Assessment (PISA) on problem solving test is below to the global average score as compared to other countries [1, 2]. This may be due to low application of higher order thinking skills upon solving open-ended problems in Malaysian schools as one of the factors [3].

Scientific competency consists of three domains of identifying the scientific issue, explaining phenomenon scientifically and using the scientific evidence to justify the solution. These competencies are crucial to enable students to accomplish the problem give critically. Normally, if the students cannot solve the question given immediately, then it is considered as a problem. This problem is regarded as an open- ended if the data, method or goal is not known [10]. In order to compete with the best in the world, the education system must develop young Malaysian who are knowledgeable, able to think critically, innovative and creative, have leadership qualities and problem solving skills that enable them to communicate with the rest of the world. In conjunction to this, problem-solving competency becomes a central objective within the educational programme of many countries such as Shanghai (China), Hong Kong, Singapore, Japan and Finland because the acquisition of increased levels of problem-solving competency provides a basis for future learning, for effective participation in society and for conducting personal activities [4].

\subsection{OBJECTIVES}

The research aims to investigate how secondary school students solve open-ended problems in learning electrolysis and identify the underlying factors of their problem-solving competency. The research questions are:

(i) What is the level of problem solving ability among school students in chemistry?

(ii) What is the problem solving process practiced by students in solving open-ended problems in chemistry?

(iii) What are the underlying factors that contribute in in developing of the problem-solving competency? 


\subsection{METHODOLOGY}

This case study has concurrently gathered both quantitative and qualitative data. Creswell (2014) stated that mixed method is a study that has both quantitative and qualitative data and both data provide a better understanding of the research problem than either type in itself. This study has collected a quantitative data using chemistry problem solving ability test (CPSAT) and qualitative approach with explanatory design. 112 of chemistry students (16-17 years) from two full residential secondary schools in Sarawak were purposefully selected due to homogenous high academic achievement. This CPSAT was administered a week in advance from the interview session was conducted. Semi-structured interviews and think aloud protocol (TAP) were conducted to five selected participants based on their CPSAT achievement to investigate the problem solving processes practiced by the respective participant.

\subsection{RESULTS AND DISCUSSION}

\section{Level of Chemistry Problem Solving Ability}

Chemistry problem solving ability test was used as an instrument to measure the level of problem solving ability to solve the open- ended problem. The performance of the test was categorized into three levels (low, average and high) based on their scores in percent in the test: 0-33 categorized as low, 34-66 as average and 67-100 as high achiever. Table 1 showed the result of the selected participants in this study.

Table 1 Chemistry Problem Solving Ability Test (CPSAT) for electrolysis

\begin{tabular}{cccc}
\hline Achievement Level & Range (\%) & Frequency & Percent (\%) \\
\hline Weak & $0-33$ & 23 & 21 \\
Average & $34-66$ & 60 & 54 \\
High & $67-100$ & 29 & 26 \\
\hline
\end{tabular}

Results obtained from the preliminary study found that chemistry problem solving ability scale, generally, indicates low (20.5\%) and average (53.6\%) and high $25.9 \%$ (29) level of performance in achievers $(\mathrm{N}=112)$ as shown in Table 1. Therefore, the overall level of problem solving ability of the participants are average. Table 2 shows the students' achievement for the respective four items in the CPSAT. They have attained average level for three out of four items (1,2 and 4). For Item 1, the mean score of the participants is 13 while the full mark is 20 ; hence, the achievement level for this item is average.

Table 2 Mean score and achievement level of each item in CPSAT

\begin{tabular}{|c|c|c|c|c|c|c|}
\hline$\stackrel{\Xi}{\Xi}$ & Scientific knowledge & Scientific competency & Full Mark & $\begin{array}{l}\text { Mean } \\
\text { Score }\end{array}$ & Achievement level & $\begin{array}{l}\text { Standard } \\
\text { Deviation }\end{array}$ \\
\hline 1 & Electrolysis of aqueous solution & $\begin{array}{c}\text { Explaining phenomena } \\
\text { scientifically }\end{array}$ & 20 & 13 & Average & 5.321 \\
\hline 2 & Electrolyte and non-electrolyte & Identify scientific issue & 8 & 4 & Average & 2.206 \\
\hline \multirow{3}{*}{3} & \multirow[t]{3}{*}{ Electrolysis of molten compound } & Identify scientific issue & \multirow{3}{*}{12} & \multirow{3}{*}{3} & \multirow{3}{*}{ Low } & \multirow{3}{*}{3.944} \\
\hline & & $\begin{array}{l}\text { Explaining phenomena } \\
\text { scientifically }\end{array}$ & & & & \\
\hline & & Using scientific evidence & & & & \\
\hline \multirow{4}{*}{4} & \multirow[t]{4}{*}{ Uses of electrolysis in industry (Rusting) } & Identify scientific issue & \multirow{4}{*}{10} & \multirow{4}{*}{4} & \multirow{4}{*}{ Average } & \multirow{4}{*}{2.365} \\
\hline & & $\begin{array}{c}\text { Explaining phenomena } \\
\text { scientifically }\end{array}$ & & & & \\
\hline & & Using scientific evidence & & & & \\
\hline & & Creating solution & & & & \\
\hline
\end{tabular}

By referring to the Table 2, question from Item 1 is regarding the "factors that are affecting electrolysis". For Item 2, the achievement level is also average given the mean score is only 4 out the 8; the full mark. Questions for Item 2 are based on the sub topic of "electrolyte and non-electrolyte". The mean score is 4 while the full mark is 10 . Meanwhile, for Item 3 , the achievement level is low where the mean score of the participants is only 3 compared to the full mark; 12. Question Item 3 was about electrolysis of molten compound. Most of the participants are unable to solve this question due to misconception about the type of substance used as the electrolyte.

Participants have a basic knowledge of chemical terms such as anode, cathode, anion, cation, electrolyte and non-electrolyte but did not recognise the relationship of conceptual knowledge to explain the phenomenon scientifically, thence unable to apply the knowledge or making justification [4]. They are able to identify the scientific issue for almost of the questions except question 3 . This scenario indicates that they still lack in high order thinking skills to solve the problem in learning chemistry. 
Table 3 showed the result of five selected participants based on their achievement in CPSAT ( 2 average and 3 low) in this case study to investigate the problem solving process practiced by them in solving open-ended problems in electrolysis and find out underlying factors required to develop problem-solving competency among participants in learning electrolysis.

Table 3 Participant's score item in chemistry problem solving ability test (CPSAT)

\begin{tabular}{cccccccc}
\hline Participant & Item 1 & Item 2 & Item 3 & Item 4 & Score & \multicolumn{2}{c}{ Score Mark } \\
$\%$ & & & & Achievement Level \\
S1 & 17 & 7 & 3 & 3 & 30 & 60 & Average \\
S2 & 18 & 6 & 0 & 7 & 31 & 62 & Average \\
S3 & 3 & 0 & 0 & 1 & 4 & Low & Low \\
S4 & 1 & 1 & 1 & 0 & 3 & Low \\
S5 & 7 & 1 & 0 & 3 & 11 & 22 & L \\
\hline
\end{tabular}

\section{Problem Solving Process to Solve the Electrolysis Questions}

Data gathered from the interview with the selected participants have showed the processes applied to solve the problem. Participants have showed and explained the steps to solve item 1 during the interview (Think Aloud Protocol). Those responses (processes) were categorized based on four phases in SSCS model (Pizzini, 1996). These four cyclic phases in SSCS model are search, solve, create and share the solution.

Table 3 Process practiced by the participants to solve open-ended

\begin{tabular}{|c|c|}
\hline Theme (Process) & Responses \\
\hline $\begin{array}{l}\text { Search the information } \\
\text { (Comprehending) }\end{array}$ & $\begin{array}{l}\text { S1-I will read word by word of the question and highlight those key words. It helps me to understand the } \\
\text { question } \\
\text { S2-Read question and highlight some words in the questions } \\
\text { S3-Read question and identify the anode and cathode based on battery terminal. } \\
\text { S4-Highlight the concentration of solution as well as the electrolyte } \\
\text { S5-Highlight the concentration to figure out whether the solution is concentrate. Identify the anode and } \\
\text { cathode and list down the anions and cations. }\end{array}$ \\
\hline $\begin{array}{c}\text { Solve } \\
\text { (Concept relatedness and } \\
\text { idea association) }\end{array}$ & $\begin{array}{l}\text { S1-Then I will recall the relevant concept and apply concept to answer the question. The length of the } \\
\text { answer is written based on the mark allocated. } \\
\text { S2-Apply my understanding about the concept of position of ion in Electrochemical Series and the } \\
\text { concentration of solution. } \\
\text { S3-Actually I don't know how to solve this question.....it's difficult. } \\
\text { S4-I got it wrong, I'm confuse this with voltaic cell. } \\
\text { S5-I need to list down all ions present in the hydrochloric acid. Then choose which ions will be } \\
\text { discharged. }\end{array}$ \\
\hline Creating solution & $\begin{array}{l}\text { S1-Consider the factors that affecting the products at the electrode, whether position of ions in } \\
\text { Electrochemical Series, concentration of electrolyte (halide ion) or type of electrode used. Then decide } \\
\text { the factor to solve the problem in detail. } \\
\text { S2. Understood the difference of gas produced at the electrode. Able to do simple half equation at } \\
\text { electrode. }\end{array}$ \\
\hline Sharing the solution & $\begin{array}{l}\text { S1- Finally, check the answer with friends and teacher. } \\
\text { S2-I will teach my other friends the solution or ask teacher if cannot get the right solution. }\end{array}$ \\
\hline
\end{tabular}

Two participants (S1 and S2) are able to show the solving process and strategy in detail. Both participants are average achiever in chemistry problem solving ability test. Participants tend to read the problem to comprehend the problem. Then they can state the observations and products at the respective electrode correctly. They are able to apply the appropriate concepts to solve the question that required explanation and justification. The participants succeeded in identifying the affect when the other factor was manipulated in the electrolysis. The other three participants (S3, S4 \& S5) with low score in the test did not share their process to solve the problem because they failed to do so.

Problem solving process that practiced by the participant is a part of problem recognition skill. Successful problem solver was need to apply problem translating skill based own their prior solving experience [11]. Problem translating skill will lead the participant to highlight in the problem statement, key pieces of information needed for its solution, describe what it means in their own words, diagram, and chemical equation, list the steps used to solve the problem and try to write the same problem but use other words. This problem translating skill required participants to comprehend, analyse, interpret and define the problem before they reach the solution.

The second cognitive process involved is linkage; how the participants relate the concept and associate the idea to solve the problem. Idea association will measure the ability to associate ideas concept, words, diagrams or equations through the use of linkage methods. Cognitive structures of good problem solver are more complex and contain more association. Creating and sharing solution are part of skills in the evaluation process. Basically, those three aspects of linkage are essential in learning and solving process; (1) internal linkage in cognitive structure, (2) activation of a particular part of cognitive structure for learning (3) external linkage between an existing cognitive structure and the new learning content. Table 4 summarize the comparison of problem solving process (PSP) between average and low achievers. 
Table 4 Comparison of problem solving process (PSP) between average and low achievers

\begin{tabular}{|c|l|l|}
\hline \multirow{2}{*}{ Problem solving process } & \multicolumn{2}{|c|}{ Achievement level in CPSAT } \\
\cline { 2 - 3 } Search & $\begin{array}{l}\text { Average } \\
\text { Comprehend the problem by identifying } \\
\text { the keywords from the problem, e.g: } \\
\text { identify the anode and cathode based on } \\
\text { battery terminal. }\end{array}$ & $\begin{array}{l}\text { Read those relevant keywords from the } \\
\text { problem. }\end{array}$ \\
\hline Solve & $\begin{array}{l}\text { They tend to plan the strategy technically } \\
\text { from the mark allocation. }\end{array}$ & $\begin{array}{l}\text { Lack of knowledge and skill to solve the } \\
\text { problem. }\end{array}$ \\
\hline Create & $\begin{array}{l}\text { Create the solution based on the principle } \\
\text { and concept applied. }\end{array}$ & $\begin{array}{l}\text { Lack of scientific knowledge and conceptual } \\
\text { understanding to create the solution. }\end{array}$ \\
\hline Sharing & $\begin{array}{l}\text { Practice collaborative problem solving to } \\
\text { gain the guidance and find solution. }\end{array}$ & Lack of understanding to share the solution. \\
\hline
\end{tabular}

Table 4 shows the comparison of processes that applied by different level of achievement in the test. Different levels of achievement depend on some factors. Thence researcher has posed questions to the selected participant on the factors that affected their ability to solve the problems and discussed in detail.

\section{Potential Factors to Enhance the Chemistry Problem Solving Competency}

Based on the participants' experience to solve the problems, the data was analysed to identify the core factors to improve their problem solving competency in order to solve them correctly. Participants have stated several factors that can potentially improve their problem solving competency based on their learning experience (Table 5.).

Table 5 Potential factors to enhance the chemistry problem-solving competency

\begin{tabular}{|c|c|}
\hline $\begin{array}{l}\text { Theme } \\
\text { (Factors) }\end{array}$ & Responses \\
\hline Knowledge & $\begin{array}{l}\text { S1- The most important thing is understand the concept and having the knowledge } \\
\text { S2- Need knowledge on how to answer correctly } \\
\text { S3- Understand the concept } \\
\text { S4- Learn to differentiate electrolytic cell and voltaic cell } \\
\text { S5-Have more knowledge on the concept to be able to put ideas into words when answering questions especially on } \\
\quad \text { electroplating and electrolyte }\end{array}$ \\
\hline $\begin{array}{l}\text { Familiarity with the } \\
\text { problem }\end{array}$ & $\begin{array}{l}\text { S1 - I need to do more exercise and identify the pattern of the problem. } \\
\text { S2 - Know the pattern for open ended question. } \\
\text { S3 - Read more and do more exercise } \\
\text { S4 - Preparation } \\
\text { S5 - More exercise }\end{array}$ \\
\hline Problem solving skills & $\begin{array}{l}\text { S1-Use the skills that we have learned during the workshop about technique to answer the question accurately. } \\
\text { S2- We should analyse the problem, then we can master the skill } \\
\text { S3-Learn how to get more marks }\end{array}$ \\
\hline Collaborative & $\begin{array}{l}\text { S1 - I prefer to discuss with friends to answer this kind of question } \\
\text { S2 - Ask friends who have better knowledge } \\
\text { S3 - To work in group as some of us cannot study and solve the problem alone } \\
\text { S4 - I am weak in this chapter. I am always getting help from friends that know better. } \\
\text { S5 - I am confused when learning alone. So, when I am solving this question with friends they can teach me to answer it. }\end{array}$ \\
\hline
\end{tabular}

From the Table 5, the potential factors to enhance the chemistry problem solving process are scientific knowledge, familiarity with the problem, the problem solving skills and collaborative activity. Scientific knowledge is a core success factor to solve the openended problem supported by application of the appropriate problem solving skills and solve it collaboratively. Scientific knowledge is knowledge that directly related to the problem about electrolysis, electrolytic cell, factors that affecting the products of electrolysis and application of electrolysis in industry will lead the participant to find out the correct solution. Lack of appropriate knowledge about electrolysis will hinder problem solving competency.

At the same time, participants must be familiar in solving those open-ended problems. Prior knowledge and formal reasoning ability were both significantly related to solve the chemistry problems. Familiarity level with the problems also may affect the ability of participants to solve them. Most of the trend in Malaysian education is to use the routine questions from the text books and test paper. The participants are unfamiliar open-ended problems which are non-routine and ill-defined. When students found out that those type of problems are not familiar, then they tends to skip without comprehending and solving it. But if they found out the problems are similar to the questions in previous test or used in text book, then the participant will solve them.

Problem solving skills are essential to solve those open-ended problems because the participants have to comprehend, analyze, interpret and define the problem well. In our real life, most problem solving happens in groups such as work team and family. Solving the problems in group or by working collaboratively will share information, exchanging other's experiences, generating inferences about data and gather more options of solution. Thence, this recent authentic input from the local school students were useful for researchers to design and develop the module in order to enhance their problem solving competency in learning chemistry. 


\subsection{CONCLUSION}

Problem solving competency is crucial to generate a competent future leader to solve the real world problems specifically regarding chemistry in context. Deep understanding of scientific knowledge competencies, problem solving skills, familiarity in solving open-ended problem and solving problems collaboratively, are identified as the potential factors to develop chemistry problem solving competency. Thence, "Module of Authentic Chemistry Problem-solving Competency" was developed by integrating those potential factors as the variables in the authentic learning practice [5].

\section{References}

Surif, J., Ibrahim, N.H \& Dalim, S.F. (2014). Problem Solving: Algorithms and Conceptual and Open-ended Problems in Chemistry. Procedia and Behavioural Sciences. 116, 4955-4963.

Lartson, C. A. (2013). Effects of Design-Based Science Instruction on Science Problem-Solving Competency Among Different Groups of High-School Traditional Chemistry Students (Doctoral Dissertation). University of Colorado.

OECD. (2006). Assessing Scientific, Reading and Mathematical Literacy: A Framework for PISA 2006, Paris: OECD Publishing.

Boži, M., \& Tramullas, M. T. E. (2014). Engineering Practice : Teaching Ill-Structured Problem Solving in an Internship-Like Course, (April), 721-726

Herrington, J., \& Oliver, R. (2000). An Instructional Design Framework for Authenticlearning Environments. Educational Technology Research and Development, $48(3), 23-48$

Pizzini, E. (1987). Project STEPS: Science Textbook Extensions through Problem Solving. Washington, DC: National Science Foundation

OECD (2012). PISA 2012 Assessment and Analytical Framework. Mathematics, Reading, Science, Problem Solving and Financial Literacy. Paris: OECD Publishing.

Gayon, P (2008), Education The Problem Solving Ability of High School Chemistry Students and Its Implication in Redefining Chemistry (Abstract). Philphines: Book of Abstracts.

Johnstone, A.H. (2000). Teaching Chemistry - Logical or Psychological? Journal Chemistry Education: Research and Practice in Europe, 1(1), 9-15.

Johnstone, A.H. (1993). Introduction. In: C. Wood \& R. Sleet (Eds) Creative Problem Solving in Chemistry (London, The Royal Society in Chemistry).

Scottish Qualification Authority. (1997). Scottish Certificate of Education Standard Grade Arrangements in Biology, Chemistry and Physics, General and Credit Levels in and after 1999. Dalkeith: Scottish Qualifications Authority. 